\title{
A GENETIC STUDY OF DAY-LENGTH RESPONSE IN WHEAT
}

\author{
C. N. LAW, J. SUTKA* and A. J. WORLAND \\ Plant Breeding Institute, Cambridge, England
}

Received 20.iv.78

\section{SUMmary}

\begin{abstract}
Using " alien" chromosome substitution lines of the wheat variety Chinese Spring (CS), it was found that the chromosomes of homoeologous group 2 were important in determining the time to ear-emergence under different day lengths. In terms of their ability to produce plants insensitive to different day lengths, chromosome $2 \mathrm{~B}$ of CS was the most potent, followed by $2 \mathrm{~A}$ of $\mathrm{CS}$, $2 \mathrm{M}$ of Aegilops comosa, 2Cu of Ae. umbellulata, $2 \mathrm{D}$ of $\mathrm{CS}$ and finally $2 \mathrm{R}^{\mathrm{m}}$ of Secale montanum. Dominant epistasis towards insensitivity was observed.
\end{abstract}

\section{INTRODUGTION}

AN important feature of the common bread wheat, Triticum aestivum $(2 n=6 x=42)$ is its wide adaptability. Wheat originated in the Middle East, but is grown today in most parts of the world. It exists in a number of forms, some of which are evidently the result of selection for particular environmental conditions. An example of this is the division of wheat into winter and spring forms by "vernalisation" genes which impose upon winter wheats the need for a cold treatment before spike and flower development can proceed (Pugsley, 1972; Law, Worland and Giorgi, 1976). This is an effective adaptive mechanism which ensures that these critical developmental stages are protected from very low temperatures.

The ability of wheat to respond to different day lengths is also another example of adaptability. Wheat is normally classified as a quantitative long-day plant (Vince-Prue, 1975) in that flowering is accelerated by the transfer to long days. However, cultivars of wheat exist which flower rapidly under short- and long-day conditions whereas other wheats will develop only slowly under short days. These day-length "insensitive" wheats are essential to the agriculture of many countries where more than one harvest a year is required or high summer temperatures restrict the growing of wheat to the winter months. Indeed, it is often claimed that the world-wide success of the Mexican bred semi-dwarf wheats arises in part from the insensitivity of these wheats to day length (Borlaug, 1968). Even in Britain where long-day conditions obtain throughout most of the growing season, sensitivity rather than insensitivity to day length may be a useful substitute for vernalisation requirement. Winter wheats, under these circumstances, may make better use of the lengthening days of spring than those wheats whose development may be held back by a need to satisfy a vernalisation requirement.

A knowledge of the genetics of day-length response is therefore important

* Present address: Agricultural Research Institute of the Hungarian Academy of Sciences, Martonvásár, Hungary. 
in wheat breeding as well as in the understanding of wheat adaptability. Pugsley (1965, 1966) identified two dominant genes for insensitivity in crosses involving Triple Dirk. Using the chromosome substitution lines of Hope into Chinese Spring, Halloran and Boydell (1967) found four lines responding differently from Chinese Spring to day length and implicated chromosomes 1A, 4A, 6B and 7D. More recently, Welsh, Keim, Pirasteh and Richards (1973) showed by means of monosomic analysis, that the day-length insensitivity of the Mexican semi-dwarf Sonora 64 was determined by at least two major genes, $P p d 1$ and $P p d 2$, located on chromosomes 2D and 2B respectively. Klaimi and Qualset (1973) have also proposed that most of the variation in day-length response could be explained by two gene loci and multiple alleles at each of these loci.

This paper describes the behaviour of a series of "alien" chromosome substitution lines for the chromosomes of homoeologous group 2 of wheat grown under different day-length and vernalisation regimes in controlled environment cabinets. These "alien" substitution lines were chosen, in part to follow up the previous work (loc. cit) and partly because three complete sets of substitutions were available for each of the homoeologues of this group in Chinese Spring.

\section{Materials AND METHOdS}

(i) The genotypes

The following "alien" substitution lines were used in which chromosomes 2Cu, 2M and 2Rm from Aegilops umbellulata, Aegilops comosa and Secale montanum respectively were substituted for their homoeologues in the variety Chinese Spring (CS).
1. $\operatorname{CS} 2 \mathrm{~A}\left(2 \mathrm{C}^{u}\right)$
6. $\mathrm{CS} 2 \mathrm{D}(2 \mathrm{M})$
2. $\mathrm{CS} 2 \mathrm{~B}\left(2 \mathrm{Cu}^{\mathrm{u}}\right)$
7. $\mathrm{CS} 2 \mathrm{~A}\left(2 \mathrm{R}^{\mathrm{m}}\right)$
3. $\operatorname{CS} 2 \mathrm{D}(2 \mathrm{Cu})$
8. $\operatorname{CS} 2 \mathrm{~B}\left(2 \mathrm{R}^{\mathrm{m}}\right)$
4. $\operatorname{CS} 2 \mathrm{~A}(2 \mathrm{M})$
9. $\mathrm{CS} 2 \mathrm{D}\left(2 \mathrm{R}^{\mathrm{m}}\right)$
5. $\mathrm{CS} 2 \mathrm{~B}(2 \mathrm{M})$
10. CS-Chinese Spring

These substitution lines were developed by V. Chapman and T. E. Miller of this Institute by backcrossing chromosome addition lines of $2 \mathrm{Cu}$, $2 \mathrm{M}$ and $2 \mathrm{R}^{\mathrm{m}}$ to the appropriate $\mathrm{CS}$ monosomes and then isolating by further backcrossing and test-crossing the "alien" substitution lines (Riley and Kimber, 1966).

\section{(ii) The experiment}

This was carried out in two controlled environment cabinets, one for the short-day and the other for the long-day treatments. In each cabinet, the plant received 8 hours of high intensity light (3800 f.c. approx.) supplied by fluorescent tubes. The day-length treatments were provided by four incandescent tubes (intensity 400 f.c. approx.); in the short-day cabinet an 8-hour treatment was used and synchronised with the high-intensity light input, whereas continuous illumination was used in the long-day cabinet. Temperatures in each of the cabinets were maintained at $18^{\circ} \mathrm{C}$ irrespective of day length. 
Half the plants in each cabinet were vernalised as germinating seed for three weeks at $4^{\circ} \mathrm{C}$ and then as seedlings for a further two weeks under short-day conditions in a cabinet also maintained at $4^{\circ} \mathrm{C}$. Following this treatment, the seedlings were transferred to $4 \frac{1}{4}$ in pots containing soil and distributed equally to each of the cabinets along with an identical number of unvernalised seedlings previously germinated at $25^{\circ} \mathrm{C}$.

In each treatment, each of the 10 genotypes was replicated four times so that each cabinet contained 80 plants. These were randomised in each cabinet and at intervals were re-randomised as the experiment progressed.

The days from the commencement of the day-length treatments to earemergence were scored for each of the plants.

\section{(iii) Analysis}

The nine "alien" chromosome substitution lines provide a balanced combination of genotypes which allow the effects of each of the "alien" chromosomes $2 \mathrm{Cu}^{\mathrm{u}}, 2 \mathrm{M}$ and $2 \mathrm{R}^{\mathrm{m}}$ to be compared as well as the effects of $2 \mathrm{~A}$, $2 \mathrm{~B}$ and $2 \mathrm{D}$ of CS. Whether these effects are additive or are dependent upon the background is an important consideration which is also capable of test. The breakdown of the variation amongst these nine genotypes to give a series of orthogonal comparisons which test for these effects is presented in table 1.

TABLE 1

Orthogonal comparisons between the nine "alien" chromosome substitution lines of homoeologous group 2 in Chinese Spring (CS)

\begin{tabular}{|c|c|c|c|c|c|c|c|c|c|c|c|}
\hline \multirow[b]{2}{*}{ Genotype } & \multicolumn{3}{|c|}{$\begin{array}{l}\text { Chromosome } \\
\text { constitution }\end{array}$} & \multicolumn{8}{|c|}{ Comparisons } \\
\hline & & & & $\{1\}$ & $\{2\}$ & $\{3\}$ & $\{4\}$ & $\{13\}$ & $\{14\}$ & $\{23\}$ & $\{24\}$ \\
\hline $\operatorname{CS} 2 A\left(2 \mathrm{C}^{\mathrm{u}}\right)$ & $2 \mathrm{C}^{\mathrm{u}}$ & $2 \mathrm{~B}$ & $2 \mathrm{D}$ & -1 & -1 & +1 & -1 & -1 & +1 & -1 & +1 \\
\hline $\operatorname{CS} 2 \mathrm{~B}\left(2 \mathrm{C}^{\mathrm{u}}\right)$ & $2 \mathrm{~A}$ & $2 \mathrm{Cu}^{\mathrm{u}}$ & $2 \mathrm{D}$ & -1 & -1 & - & +2 & - & -2 & - & -2 \\
\hline $\operatorname{CS} 2 D\left(2 C^{u}\right)$ & $2 \mathrm{~A}$ & 2B & $2 \mathrm{C}^{u}$ & -1 & -1 & -1 & -1 & +1 & +1 & +1 & +1 \\
\hline $\operatorname{CS} 2 A(2 M)$ & $2 \mathrm{M}$ & $2 \mathrm{~B}$ & 2D & +1 & -1 & +1 & -1 & +1 & -1 & -1 & +1 \\
\hline $\mathrm{CS} 2 \mathrm{~B}(2 \mathrm{M})$ & $2 \mathrm{~A}$ & $2 \mathrm{M}$ & 2D & +1 & -1 & - & +2 & - & +2 & - & -2 \\
\hline $\mathrm{CS} 2 \mathrm{D}(2 \mathrm{M})$ & $2 \mathrm{~A}$ & $2 \mathrm{~B}$ & $2 \mathrm{M}$ & +1 & -1 & -1 & -1 & -1 & -1 & +1 & +1 \\
\hline $\operatorname{CS} 2 A\left(2 R^{m}\right)$ & $2 \mathrm{R}^{\mathrm{m}}$ & $2 \mathrm{~B}$ & 2D & - & +2 & +1 & -1 & - & - & +2 & -2 \\
\hline $\mathrm{CS} 2 \mathrm{~B}\left(2 \mathrm{R}^{\mathrm{m}}\right)$ & $2 \mathrm{~A}$ & $2 \mathrm{R}^{\mathrm{m}}$ & 2D & - & +2 & - & +2 & - & - & - & +4 \\
\hline $\operatorname{CS} 2 D\left(2 R^{m}\right)$ & $2 \mathrm{~A}$ & $2 \mathrm{~B}$ & $2 \mathrm{R}^{\mathrm{m}}$ & - & +2 & -1 & -1 & - & - & -2 & -2 \\
\hline $\begin{array}{l}\{2 \\
\{3 \\
\{4\end{array}$ & $\begin{array}{l}2 \mathrm{Cu}^{\mathrm{u}} \\
2 \mathrm{R}^{\mathrm{m}} \\
2 \mathrm{Av} \\
2 \mathrm{~A}+\end{array}$ & $\int^{2 C^{u}+}$ & & & $\begin{array}{l}\{13\} \\
\{14\} \\
\{23\} \\
\{24\}\end{array}$ & $\begin{array}{l}2 \mathrm{C}^{u} \\
2 \mathrm{C}^{u} \\
2 \mathrm{Cu}^{u}\end{array}$ & $\begin{array}{l}2 \mathrm{M} / 2 \\
2 \mathrm{Mv} \\
2 \mathrm{Mv}\end{array}$ & $\begin{array}{l}1 \mathrm{D} \\
\mathrm{R}^{\mathrm{m}} / 2 \\
\mathrm{R}^{\mathrm{m}} / 2\end{array}$ & $\begin{array}{l}2 \mathrm{~B} \\
\mathrm{v} 2 \mathrm{D} \\
+2 \mathrm{D}\end{array}$ & & \\
\hline
\end{tabular}

It will be noted that the comparisons refer to the variation among either the "alien" chromosomes or the wheat homoeologues or the interactions between the two. There are no comparisons which relate directly to the differences between the wheat and "alien" homoeologues. However, it is possible to make these comparisons by introducing CS into the analysis. Thus, the difference between CS and any of the "alien" substitution lines compares the effect of the "alien" chromosome with the effect of the wheat homoeologue it is replacing. Given therefore, predominantly additive genetic variation, it is possible to compare the effect of all the homoeologues against each other and rank them according to their effectiveness. 
This ability is an important advantage that "alien" chromosome substitution lines have over inter-varietal chromosome substitutions where effects can only be referred to homologous chromosome variation and not to the absolute differences in effect which may occur between homoeologues.

\section{Results}

The overall analysis of ear-emergence time is given in table 2. The main effects for the two treatments, day-length and vernalisation, as well as genotype differences are all highly significant. However, it is the interaction items which are of principal interest in this study. Here, only the interaction of genotypes and day length is significant and there is no differential response

TABLE 2

Analysis of variance of ear emergence for the 10 genotypes grown under short-day and long-day conditions and in the unvernalised and vernalised states

\begin{tabular}{lcc}
\multicolumn{1}{c}{ Item } & d.f. & M.S. \\
Short-days $v$. long-days & 1 & $165406 * * *$ \\
Unvernalised $v$. vernalised & 1 & $10150 * * *$ \\
Interaction & 1 & 96 \\
Genotypes & 9 & $1888 * * *$ \\
Genotypes/short-days $v$. long-days & 9 & $1925 * * *$ \\
Genotypes/unvernalised $v$. vernalised & 9 & 31 \\
Genotypes/interaction & 9 & 42 \\
Residual & 115 & 24 \\
& $* * * P<0.001$ &
\end{tabular}

of the genotypes to vernalisation. The genes which are being varied as a result of the substitution of the group 2 chromosomes are consequently sensitive to day-length but not to vernalisation. The significant main effect of vernalisation evidently comes from genes which are common to all the genotypes and possibly relate to the known genes for vernalisation requirement on the group 5 and 7 chromosomes (Law et al., 1976).

TABle 3

The separate analyses of variance of ear-emergence time for the short-day and long-day treatments

\begin{tabular}{|c|c|c|c|}
\hline Item & d.f. & $\begin{array}{c}\text { M.S. } \\
\text { short-days }\end{array}$ & $\begin{array}{c}\text { M.S. } \\
\text { 1ong-days }\end{array}$ \\
\hline Unvernalised $v$. vernalised & 1 & $6116 * * *$ & $4133 * * *$ \\
\hline Genotypes & 9 & $3804 * * *$ & $10 *$ \\
\hline Genotypes/unvernalised $v$. vernalised & 9 & 55 & $17 * * *$ \\
\hline Residual & 60 & $46+$ & 4 \\
\hline
\end{tabular}

The further breakdown of the day-length differences and their interaction with genotypes is given in table 3 and indicates that these are due predominantly to the variation among the genotypes within the short-day treatments. Despite the significance of the genotypes/unvernalised $v$. vernalised interaction, the genotype variation within the long-day treatment is very small compared to the very large genotype differences that occur 
within the short-day treatment. It is thus only under the conditions of short days that differences in ear-emergence time between the genotypes are strikingly apparent.

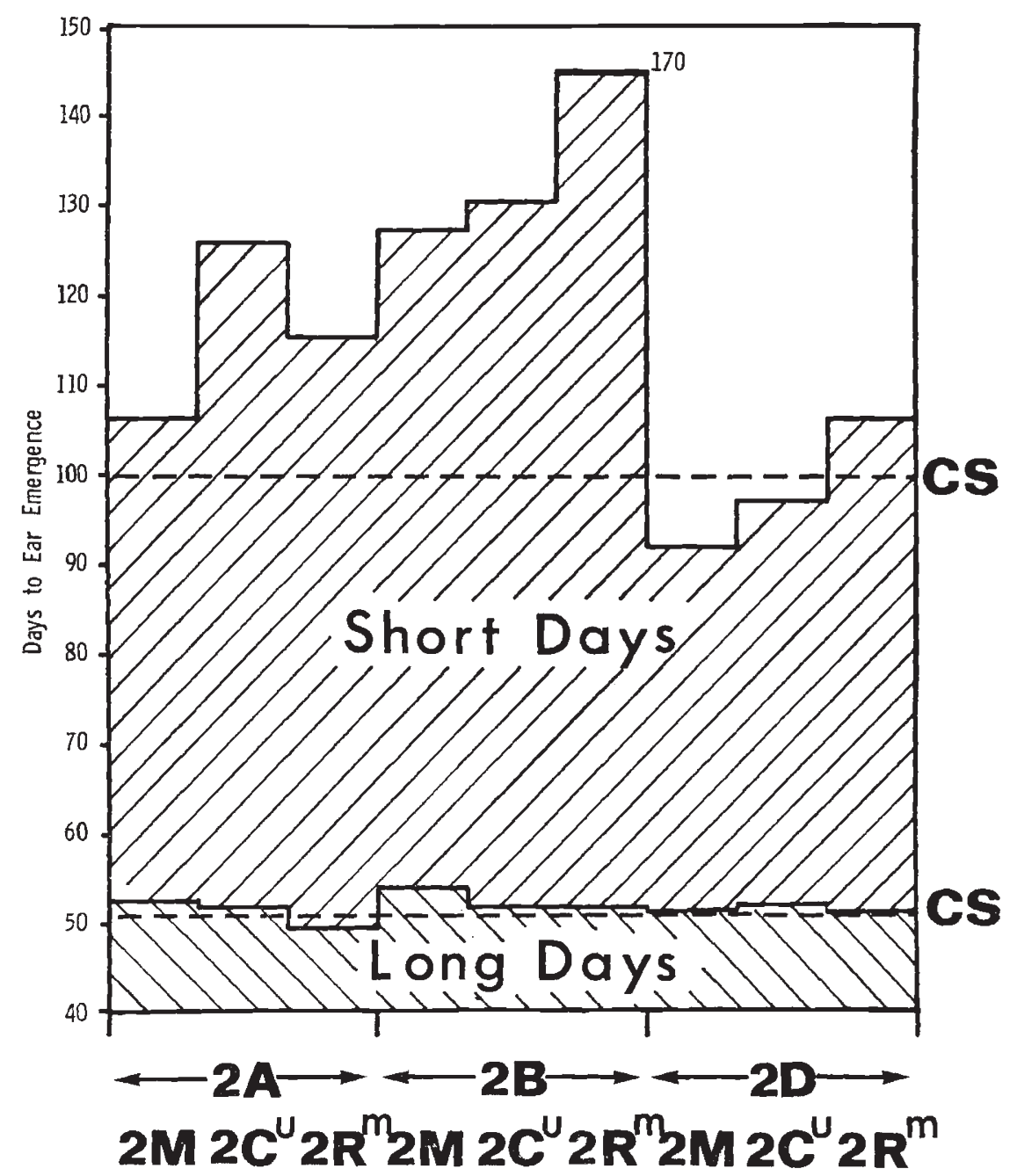

Fig. 1.-Mean ear-emergence times for the nine "alien" substitution lines and Chinese Spring (CS) under short and long days. The substitutions of either chromosome 2M, $2 \mathrm{C}^{\mathrm{u}}$ or $2 \mathrm{R}^{\mathrm{m}}$ for $2 \mathrm{~A}$ are presented first in the figure, followed by the same substitutions for $2 \mathrm{~B}$ and then for $2 \mathrm{D}$.

The mean ear emergence times for the nine "alien" substitution lines and CS under short-days and long-days and with the different vernalisation treatments pooled are given in fig. 1. The analysis of the variation among these lines under short-days is shown in table 4 and uses the scheme for identifying particular chromosome effects described in the Methods. All the main effects of this analysis are highly significant, the comparison involving chromosome $2 \mathrm{~B}$ being outstanding, whereas only the interaction of $2 \mathrm{~B}$ with $2 \mathrm{R} \mathrm{m}$ appears to be of importance. It is thus possible to rank the 
TABLE 4

The analysis of the genotype variation among the nine "alien" chromosome substitution lines

\begin{tabular}{|c|c|c|c|}
\hline Item & d.f. & & M.S. \\
\hline Unvernalised $v$. vernalised & 1 & - & $5264 * * *$ \\
\hline Genotypes & 8 & - & $3524 * * *$ \\
\hline$\{1\} 2 \mathrm{Cu}_{\mathrm{v}} 2 \mathrm{M}$ & 一 & 1 & $1045 * * *$ \\
\hline$\{2\} 2 \mathrm{C}^{\mathrm{u}}+2 \mathrm{Mv} 2 \mathrm{R}^{\mathrm{m}}$ & - & 1 & $3553 * * *$ \\
\hline$\{3\} 2 A v 2 D$ & - & 1 & $3996 * * *$ \\
\hline$\{4\} 2 A+2 D v 2 B$ & - & 1 & $18618 * * *$ \\
\hline$\{13\} 2 \mathrm{Cu}^{\mathrm{u}} 2 \mathrm{M} / 2 \mathrm{Av} 2 \mathrm{D}$ & - & 1 & $406 *$ \\
\hline$\{14\} 2 \mathrm{Cu}^{\mathrm{v}} 2 \mathrm{M} / 2 \mathrm{~A}+2 \mathrm{Dv} 2 \mathrm{~B}$ & _- & 1 & 241 \\
\hline$\{23\} 2 \mathrm{C}^{\mathrm{u}}+2 \mathrm{Mv} 2 \mathrm{R}^{\mathrm{m}} / 2 \mathrm{Av} 2 \mathrm{D}$ & - & 1 & 287 \\
\hline$\{24\} 2 \mathrm{Cu}^{\mathrm{u}}+2 \mathrm{Mv} 2 \mathrm{R}^{\mathrm{m}} / 2 \mathrm{~A}+2 \mathrm{Dv} 2 \mathrm{~B}$ & - & 1 & $3603 * * *$ \\
\hline Genotypes/unvernalised $v$. vernalised & 8 & & 60 \\
\hline$* P=0.05-0.01$ & .001 & *: & 0.001 \\
\hline
\end{tabular}

effects of each of the chromosomes in terms of their ability to respond to short-days. For the three "alien" chromosomes, plants with $2 \mathrm{M}$ substituted are consistently earlier than plants with $2 \mathrm{C}^{\mathrm{u}}$, whereas plants with $2 R^{m}$ are much later than either. The effect of $2 \mathrm{M}$ is therefore to reduce plant sensitivity to day-length, i.e. the difference between long-day and short-day ear-emergence is reduced, whereas $2 \mathrm{Rm}$ increases plant sensitivity. A similar classification can also be made for the group 2 chromosomes of CSS where in terms of insensitivity the effects of $2 \mathrm{~B}>2 \mathrm{~A}>2 \mathrm{D}$.

To combine both sets of rankings it is necessary to consider the behaviour of CS. All the substitution lines for $2 \mathrm{~A}$ and $2 \mathrm{~B}$ are later in ear-emergence time under short days than CS (see fig. 1), so clearly $2 \mathrm{M}, 2 \mathrm{C}^{\mathrm{u}}$ and $2 \mathrm{R}^{\mathrm{m}}$ produce effects for sensitivity which are greater than $2 \mathrm{~A}$ and $2 \mathrm{~B}$. On the other hand, $\operatorname{CS} 2 \mathrm{D}(2 \mathrm{M})$ and $\mathrm{CS} 2 \mathrm{D}\left(2 \mathrm{C}^{\mathrm{u}}\right)$ are both earlier than $\mathrm{CS}$ so $2 \mathrm{M}$ and $2 \mathrm{C}^{u}$ have effects towards insensitivity greater than $2 \mathrm{D}$. C.S2D $\left(2 \mathrm{R}^{\mathrm{m}}\right)$ is later than CS, so that among the chromosomes studied the greatest sensitivity must be conferred by $2 \mathrm{R}^{\mathrm{m}}$. Overall, therefore, the rankings of the six group 2 chromosomes expressed in terms of their ability to produce insensitivity to day length are $2 \mathrm{~B}>2 \mathrm{~A}>2 \mathrm{M}>2 \mathrm{C}^{\mathrm{u}} \geqq 2 \mathrm{D}>2 \mathrm{R}^{\mathrm{m}}$.

The significant interaction effect in table 4 involves $2 B$ and $2 R m$, the chromosomes at either end of the rankings. This interaction turns out to be positive $(+7.96)$ as indeed do both the estimates of the effects of the two chromosomes $\left(+17.06\right.$ for $2 \mathrm{~A}+2 \mathrm{Dv} 2 \mathrm{~B}$ and +7.45 for $\left.2 \mathrm{R}^{\mathrm{m}} \mathrm{vC}^{\mathrm{u}}+2 \mathrm{M}\right)$. This combination of positive effects indicate that $2 \mathrm{~B}$ promotes earliness and reduces the variation between genotypes under short days, whereas $2 \mathrm{R}^{\mathrm{m}}$ has the reverse effect. In this respect therefore the action of $2 \mathrm{~B}$ is identical to that of the dominant gene in dominant epistasis. It is worth noting that this type of epistasis was observed to occur between the photoperiod genes studied by Welsh et al. (loc. cit).

\section{Discussion}

All the chromosomes of homoeologous group 2 carry genes which are sensitive to reduced day-lengths. This agrees with the reported location of the genes, $P p d 1$ and $P p d 2$ on chromosomes $2 \mathrm{D}$ and $2 \mathrm{~B}$ respectively by Welsh et al. (1973), and also indicates that at least a third locus, $P p d$ 3, should be assigned to chromosome 2A. Because all three chromosomes of group 2 are involved it would seem very likely that the three loci are homoeo- 
allelic and are functionally very similar. The extreme effect that chromosome $2 \mathrm{~B}$ of $\mathrm{CS}$ has on day-length insensitivity suggests that the winter-habit gene located on chromosome $2 \mathrm{~B}$ in a number of varieties by Tsunewaki (1966) is in fact a day-length sensitive gene also, since $F_{2}$ monosomic analysis using CS as the recipient was used in making these locations.

Reports that plants ditelosomic for long-arm of $2 \mathrm{~B}$ and therefore deficient for the short-arm of CS are delayed under short-day conditions (Boyd, 1974; McIntosh, personal communication) suggest that insensitivity is due to the presence of a gene rather than to its absence. They may also suggest that $P p d 2$ is located on the short-arm of $2 \mathrm{~B}$.

Apart from the major adaptive role that these genes have in wheat, the consequences of the substitution of day-length genes on characters other than the time to flowering are not known. For most wheat varieties, loss of any of the group 2 chromosomes, as in monosomics $(2 n=41)$, produces marked reductions in plant height (Law and Worland, 1973). The stages of leaf development, stem elongation and meiosis are not as well synchronised in these monosomics as in other monosomics or in the euploid (Law, unpublished). Also, these monosomics have reduced amounts of endogenous gibberellic acid (Gale and Law, 1973), a hormone whose level is influenced markedly by different day lengths (Vince-Prue, 1975). The association of altered gibberellic acid levels and varying plant heights, as well as asynchronous development, could therefore be related to the control that these chromosomes have on plant day-length response. A detailed analysis of the effects of varying the $P p d$ genes whilst maintaining a constant genetic background, as is possible using intervarietal chromosome substitution lines, should allow this intriguing possibility to be tested.

\section{References}

BORlaug, N. E. 1968. Wheat breeding and its impact on world food supply. Proc. 3rd Int. Wheat Genet. Symp., Canberra, 1-36.

BOYD, w. J. R. 1974. Studies with substitution lines. EWAC Newsletter, 4, 66.

GALE, M. D., AND LAW, C. N. 1973. Semi-dwarf wheats induced by monosomy and associated changes in gibberellin levels. Nature, 241, 211-212.

HALLORAN, G. M., AND BOYDELL, C. W. 1967. Wheat chromosomes with genes for photoperiodic response. Can. 7. Genet. Cytol., 9, 394-398.

KLAIMI, צ. Y., AND QUALSET, C. O. 1973. Genetics of heading time in wheat (Triticum aestivum L). I. The inheritance of photoperiodic response. Genetics, 74, 139-156.

LAW, C. N., AND woRlAND, A. J. W. 1973. Aneuploidy in wheat and its uses in genetic analysis. Annual Rep. Plant Breeding Institute, 1972, pp. 25-65.

LAW, C. N., WORLAND, A. J. W., AND GIORGI, B. 1976. The genetic control of ear-emergence time by chromosomes $5 \mathrm{~A}$ and $5 \mathrm{D}$ of wheat. Heredity, $36,49-58$.

PUGSLEY, A. T. 1965. Inheritance of a correlated day-length response in spring wheat. Nature, 207, 108.

PUGSLEY, A. T. 1966. The photoperiodic sensitivity of some spring wheats with special reference to the variety Thatcher. Aust. F. Agric. Res., 17, 591-599.

pugsley, A. T. 1972. Additional genes inhibiting winter habit in wheat. Euphytica, 21, 547-552.

RILEY, R., AND KIMBER, G. 1966. The transfer of alien genetic variation to wheat. Annual Rep. Plant Breeding Institute, 1964-65, pp. 6-36.

TSUNEWAKI, K. 1966. Comparative gene analysis of common wheat and its ancestral species. II. Waxiness, growth habit and awnedness. Jap. F. Bot., 19, 175-229.

vINCE-PRUE, D. 1975. Photoperiodism in Plants. McGraw Hill, London.

WELSH, J. R., KEIM, D. L., PIRASTEH, B., AND RICHARDS, R. D. 1973. Genetic control of photoperiod response in wheat. Proc. 4th Int. Wheat Genet. Symp., Missouri, 879-884. 